\title{
FRACTURE RESPONSE ENHANCEMENT OF ALUMINUM USING IN-SITU SELECTIVE REINFORCEMENT
}

\author{
Christopher H. Abada ${ }^{1}$ \\ National Institute of Aerospace \\ NASA Langley Research Center \\ Mechanics of Structures and Materials Branch \\ Hampton, VA 23681 \\ Gary L. Farley. ${ }^{2}$ \\ Army Research Laboratory \\ Vehicle Technology Directorate \\ NASA Langley Research Center \\ Mechanics of Structures and Materials Branch \\ Hampton, VA 23681 \\ and \\ Michael W. Hyer ${ }^{3}$ \\ Department of Engineering Science and Mechanics \\ Virginia Polytechnic University and State University \\ Blacksburg, VA 24061
}

\begin{abstract}
A computer-based parametric study of the effect of reinforcement architectures on fracture response of aluminum compact-tension (CT) specimens is performed. Eleven different reinforcement architectures consisting of rectangular and triangular cross-section reinforcements were evaluated. Reinforced specimens produced between 13 and 28 percent higher fracture load than achieved with the unreinforced case. Reinforcements with blunt leading edges (rectangular reinforcements) exhibited superior performance relative to the triangular reinforcements with sharp leading edges. Relative to the rectangular reinforcements, the most important architectural feature was reinforcement thickness. At failure, the reinforcements carried between 58 and 85 percent of the load applied to the specimen, suggesting that there is considerable load transfer between the base material and the reinforcement.
\end{abstract}

\section{Introduction}

Cost and performance requirements of commercial and military aircraft have historically driven advances in design of aircraft structure. Performance gains for metallic structures prior to the 1990s were primarily achieved through advances in aluminum alloy material properties. However, concern about the

\footnotetext{
${ }^{1}$ Graduate Student, MSMB, NASA Langley Research Center, MS 150, non-member AIAA.

2 Aerospace Engineer, MSMB, NASA Langley Research Center, MS 150, non-member AIAA.

${ }^{3}$ Professor, Dept. of Engineering Science and Mechanics, VPI\&SU, Blacksburg, VA, Fellow AIAA.
} 
adequacy of understanding of damage tolerance and durability of metallic structure has risen during the past two decades [1].

During the past four decades, research into carbon fiber reinforced composite material has sufficiently matured to warrant its application to aircraft, such as the Boeing 777 and the Air Force's F-22 fighter. Approximately 10 percent of the structural weight of the Boeing 777 is carbon fiber reinforced polymer matrix composite material [2]. From the aft pressure bulkhead rearward, including both the horizontal and vertical stabilizers, the structure is primarily composed of composite material. These aerodynamic surfaces are similar in size to the wings on the Boeing 737 aircraft, which constitutes a significant application of composite material to a commercial aircraft.

The new Boeing 787 has both composite wings and fuselage. Michael Bair, the senior Vice President of the 787 program, stated that although aluminum manufacturers offered lighter aluminum alloys than historically used, composites were chosen due to increased strength, reduced cost, light weight, “...durability, reduced maintenance requirements, and increased potential for future development", [3]. The new Airbus A380 does not make as extensive application of composite materials as the Boeing 787, however, Airbus is considering composite wings on future commercial aircraft.

Noting these examples, it is apparent that substantial momentum has developed for the application of polymeric matrix composite materials to aircraft structures, resulting in reduced market share for the aluminum industry. For the aluminum industry to successfully compete, inherent deficiencies related to damage tolerance and durability must be improved, and a potential for further performance growth and manufacturing cost reduction must be demonstrated. At the June 2004 Aeromat Conference [4], Alcoa presented their strategy to regain market share in the commercial aerospace market. They identified three enabling technologies applied in concert to achieve this goal; advanced alloys, integral stiffening, and selective reinforcement. A program was established by Alcoa to develop and validate material, structural and fabrication recipes that demonstrate a 20 percent reduction in cost and weight. This program was identified as "Alcoa's 20-20 vision".

One of Alcoa's advanced alloys is Al-Li, a class of alloys that has higher stiffness and lower density than other aerospace grade aluminum alloys. Integral stiffening, such as achieved through part extrusion and friction stir welding of parts, aids in both reducing weight as well as reducing manufacturing cost through elimination of fasteners, reduction of part count, and automation of structural assemblies. Selective reinforcement is the local application of a reinforcing material to satisfy a deficiency such as a lack of stiffness or fracture strength. Reinforcement material could constitute a small or large portion of the total structure, depending upon the complexity and size of the deficient region of the structure.

There are two methods of selective reinforcement, the lamination approach currently practiced by Alcoa, [4], and an in-situ approach as being developed by Farley et al, [5-7]. Alcoa is using fiber metal laminate (FML) as reinforcement. The FML is adhesively bonded to the interior of the wing or fuselage skin and/or stiffeners, thereby providing improvement to the inherent fatigue crack growth resistance and fracture strength of the base aluminum structure. The in-situ selective reinforcement (ISSR) technique is less mature, but offers considerable potential for performance growth. With the ISSR approach, the reinforcement (such as Nextel, boron, or coated carbon fibers) volumetrically replaces the base material.

In-situ selective reinforcement has been demonstrated to be an effective method to increase local stiffness, to improve buckling and post-buckling response, and to enhance fastener hole strength and fatigue crack growth resistance [5-7]. The improvement associated with fracture strength, although significant, was less than experienced for other requirements. It is believed that the modest increase in fracture performance with ISSR is related to reinforcement architecture (geometry and constituent materials) and possibly the through-the-thickness location within the base structure. Therefore, to demonstrate the performance growth potential of ISSR structures, it is necessary to understand the response mechanisms associated with fracture and develop reinforcement architectures that will result in significant improvement in fracture strength relative to unreinforced aluminum.

The objective of this research is to develop ISSR architectures (reinforcement geometries, constituent materials and location of reinforcement within the base material) that increase the fracture response (maximum load achieved through a compact tension test) of ISSR metallic materials relative to non-ISSR materials. A finite element analysis based parametric study of the affect of reinforcement architectures on fracture response is performed. Results presented will include the overall response trends associated with the different reinforcement architectures, the maximum load (parameter used to assess performance) associated with the different reinforcement architectures, and a discussion of the mechanisms leading to improved performance. 


\section{Approach}

The influence of eleven different reinforcement architectures on fracture response is investigated through the use of computer modeling of compact-tension specimens with different reinforcement architectures. A representative specimen used in this investigation is depicted in Figure 1a, where the applied load $\mathrm{P}$, the precrack and the analysis coordinate system are illustrated. A quarter of the compacttension specimen is illustrated in Figure 1b where the general location of the reinforcement is shown and details of the assumed symmetry of the response are specified. It will be assumed that self-similar crack growth occurs and geometric and material symmetry exists about the mid-plane (X-Y plane) and relative to the crack plane (X-Z plane), thereby reducing modeling requirements to that of a quarter-model, as represented in Figure 1b. In Figure 1c a finite element representation of the quarter model is shown. Insitu selective reinforcement volumetrically replaces the base metallic material, allowing the reinforcement to be located anywhere through the thickness of the specimen. To limit this investigation, reinforcements are located either at the outer surface or at the mid-plane of the specimen.

\section{A. Modeling and analysis}

The ABAQUS finite-element computer program [8] employing a standard analysis procedure (ABAQUS terminology for an implicit analysis), with custom-written user routines to automate crack propagation and progressive failure prediction, are used to perform all analyses in this investigation. The need to understand the influence of the reinforcement's three-dimensional architecture and the spatial location of the reinforcement on fracture response requires three-dimensional modeling the specimen. Therefore, three-dimensional solid elements (8-node hexahedron and 6-node wedge elements) are used. A representative finite-element model depicting mesh density is shown in Figure 1c. Symmetry constraints are applied to the surfaces of the $\mathrm{X}-\mathrm{Y}$ and $\mathrm{X}-\mathrm{Z}$ symmetry planes. Initial crack length is represented by not constraining nodes in the $\mathrm{X}-\mathrm{Z}$ symmetry plane starting at $\mathrm{X}=0.0$ and extending the pre-crack distance in the positive X-direction.

Both geometric and material nonlinear responses are accounted for in these analyses. The base material, that is, the primary constituent of the compact tension specimen, is represented as 7075-T6 aluminum and modeled in ABAQUS as elastic-plastic material with von Mises yielding. Reinforcements used in this investigation are composed of a unidirectional orthotropic fiber reinforced material or a combination of isotropic (1100-Al or aluminum-lithium alloy) and unidirectional orthotropic materials.

Self-similar crack growth is assumed and crack propagation in the base material is achieved by releasing nodal constraints in the Y-direction along the X-Z symmetry plane. Crack-tip opening angle (CTOA) is used to determine when the crack should propagate in the base material. An initial critical CTOA of 5.7 degrees is decreased in a quadratic manner to 4.7 degrees as the crack length increases by approximately one plate thickness $(0.1 \mathrm{in}$.). Critical CTOA is maintained at 4.7 degrees for the remainder of the crack growth. Crack-tip opening angle is computed by measuring the crack tip opening displacement (CTOD) 0.04 in. from the crack tip, as depicted in Figure 2. Variation in crack growth through-thethickness is accommodated by independently releasing constraints through the thickness of the specimen. Due to lack of CTOA data for the reinforcement material, failure of the reinforcement is based upon the fibers extensional failure strain. After initial failure of the reinforcement, the remaining reinforcement fails catastrophically [5]. Therefore, since this investigation is only focused on the maximum load, it is unnecessary to model the subsequent progressive failure.

Load introduction into the specimen is through an applied displacement at the center of the steel loadintroduction pin. The corresponding load P is determined from nodal reaction forces at the pin's center. Contact constraints are incorporated between the pin and the edge of the specimen's load introduction hole to accurately represent load transfer into the specimen.

\section{B. Reinforcement architectures}

The computer-based parametric study includes eleven different reinforcement architectures, as listed in Tables 1, 1A and 2. A unreinforced baseline case is analyzed and the calculated maximum load is used as a normalization factor for the reinforced cases. Furthermore, the yy strain across the X-Z plane is calculated for the unreinforced baseline case and compared with similar strain fields from reinforced specimens. 
Reinforcements have approximately the same cross-sectional area of $0.010 \mathrm{in}^{2}$ and are symmetrical about their Y-Z plane. Symmetry is required because in an application it is not known a priori which direction the crack will initiate and grow. Reinforcements are located either at the exterior surface or the mid-plane of the model, such as reinforcement architectures 1 and 2, respectively, depicted in Table 1. Due to symmetry, reinforcements embedded on the surface are replicated on the bottom surface, whereas the reinforcement on the symmetry plane is continuous to the symmetrical side.

The first and second reinforcement architectures have rectangular cross-section with a thickness of $0.020 \mathrm{in}$. and a width of 0.50 inches. The first reinforcement architecture is positioned at the surface of the base material where the outer surface of the reinforcement is at the surface of the specimen. This architecture is similar to that used in experiment and analysis [5]. The second reinforcement architecture is identical in cross-sectional geometry as the first architecture; however it is located at the specimen midplane. Results from the first and second reinforcement architectures provide insight into the influence of reinforcement location within the base material on fracture response.

The third reinforcement architecture has a rectangular cross-section with a thickness of $0.040 \mathrm{in}$. and a width of $0.25 \mathrm{in}$. and is located at the mid-plane of the specimen. Comparing the results from the second and third reinforcement architectures demonstrate the influence of reinforcement thickness on fracture response.

The fourth reinforcement architecture has a rectangular cross-section similar to architecture 3 except reinforcement 4 extends through the full thickness of the specimen. The thickness of reinforcement architecture 4 is $0.050 \mathrm{in}$. and the width is 0.20 inches. Comparing the results of reinforcement architecture 4 to results from architectures 1,2 and 3 completes the investigation of the effect of reinforcement thickness on fracture response. Comparing the strain fields in reinforcement architectures $1-4$ when the specimen fails also provides an indication of the influence of reinforcement width.

Reinforcement architecture 5 is full thickness similar to reinforcement architecture 4. However, in architecture 5 the width of the reinforcement is one-half that of reinforcement 4 , thus producing a crosssectional area of one-half of that in reinforcement 4 . The thickness of reinforcement 5 is 0.050 in. and the width is 0.10 inches. Comparing the results of reinforcement 5 is the results of reinforcement 4 demonstrate the influence of reinforcement width for full thickness reinforcement architectures.

The sixth reinforcement architecture is similar to the first architecture in that it is rectangular in shape and located at the specimen's surface, however the lower corners of the reinforcement are rounded, removing the corner and potentially reducing local stress concentrations associated with a corner and a change of material properties. Comparison of results from the first and sixth reinforcement architectures provides insight into how reinforcement corner geometry influences fracture response.

The seventh reinforcement architecture consists of multiple (6) uniformly-spaced reinforcement regions (rectangular cross-section due to specimen symmetry) composed of unidirectional orthotropic reinforcement positioned at the specimen's mid-plane. Cross-sectional dimensions of each reinforcement region are $0.040 \mathrm{in}$. wide by $0.040 \mathrm{in}$. high with center-to-center spacing of 0.050 inches. The total cross sectional area of the multiple reinforcements is $0.096 \mathrm{in}^{2}$ as compared to $0.10 \mathrm{in}^{2}$ for rectangular reinforcement architectures 1 through 3. Comparison of the results from the seventh with the second and third reinforcement architectures provides insight into fracture response of segmented reinforcements.

Reinforcement architecture eight is similar to architecture seven in that the reinforcement consists of uniformly-spaced reinforcement regions. However, in architecture eight there are only 3 reinforcement regions instead of 6 as is the case in architecture seven resulting in one-half of the total cross-sectional area. Comparing the results from architectures 7 and 8 provides insight into the effect of the number of reinforcement regions on fracture response.

Reinforcement architectures nine through fourteen (see Table 2) have a triangular cross section and are included in this investigation to demonstrate how geometrical (sharp vs. blunt leading edge) and material changes at the leading edge of the reinforcement influence fracture response. The height of all triangular shaped reinforcements is $0.04 \mathrm{in}$. with a total width of $0.50 \mathrm{in}$. The ninth reinforcement architecture is positioned at the specimen surface and is used to investigate the influence of the sharp leading edge as an alternative to the blunt leading edge of rectangular reinforcement, such as architecture one.

The tenth reinforcement architecture is similar to the ninth except it is positioned at the specimen's mid-plane and rotated about the $\mathrm{Y}$-axis 180 degrees. Reinforcement architectures ten through thirteen have a diamond cross-sectional shape. However because of the mid-plane symmetry, they are referred to as a triangle in this investigation. Comparison of the results from the ninth and tenth reinforcement architectures provides insight into the influence of spatial location of sharp leading edge reinforcement on 
fracture response similar to architectures one and two. Comparing the results of reinforcement ten to the results of reinforcement two also provides insight into the difference between blunt and sharp leading edge reinforcement.

Reinforcement architectures eleven through fourteen have a small region comprised of a non-7075-T6 aluminum alloy (either 1100-Al or Al-Li) at the leading edge of the triangular reinforcement. Placing aluminum alloy with a different yield stress at the tip of the triangular reinforcement is investigated to determine whether it is possible to alter fracture response to achieve higher reinforcement failure load.

The length of the aluminum region in reinforcement eleven is $0.025 \mathrm{in}$. and is composed of $1100-\mathrm{Al}$ alloy. The yield stress of 1100 alloy aluminum is less than 10 percent of the 7075-T6 aluminum base material. Reinforcement twelve is geometrically similar to eleven except the alloy region is composed of Al-Li which has a yield stress that is approximately 30 percent higher and its stiffness is approximately 10 percent higher than the base material. Comparing the results from architectures ten, eleven and twelve provides insight into the influence of how the addition of a small aluminum region at the tip of the triangular reinforcement, whose properties differs from the base material, influences fracture response.

Reinforcement architecture thirteen is geometrically and materially similar to that of eleven except the aluminum region's length in architecture thirteen is increased to 0.0625 inches, 2.5 times the length of the region in reinforcement eight. Comparing the results from reinforcements eleven and thirteen provides insight into the influence of aluminum region length at the tip of the reinforcement on fracture response.

Reinforcement fourteen is similar to reinforcement eleven except it is positioned on the specimen's surface, not its mid-plane. As is the case with reinforcement eleven, the aluminum region at the tip of the reinforcement is composed of 1100-Al alloy. Comparing the results from reinforcements eleven and fourteen provides insight into the influence of fracture response due to spatial location of the reinforcement.

\section{Materials}

The mechanical properties for the base material, steel pin and reinforcing material used in the analyses are presented in Table 3. The base material is 7075-T6 aluminum and is modeled as an elastic-plastic material using the von Mises yield criterion. The material properties of the steel pin are assumed to be linear-elastic. The reinforcement material is a unidirectional alumina-oxide fiber $\left(\mathrm{Al}_{2} \mathrm{O}_{3}\right)$ in an 1100-Al alloy matrix with a fiber volume fraction of 50 percent.

In reinforcement architectures eleven through fourteen of the triangular cross-section, reinforcement is represented as a combination of isotropic and orthotropic materials, where the isotropic material is located at the leading edge of the reinforcement. The purpose of the isotropic material is to alter the local crackgrowth response as the crack approaches the reinforcement to facilitate a higher maximum load prior to reinforcement failure. Two aluminum alloys are used in this investigation, an 1100-Al alloy and an Al-Li alloy. The 1100 aluminum alloy has similar elastic stiffness as the 7075-T6 base material except its yield stress is on the order of 10 percent of the base material. The Al-Li alloy has approximately a 30 percent higher yield stress and approximately 10 percent higher elastic stiffness than the base material.

\section{Results and Discussion}

This section is divided into three sub-sections. Results for both the unreinforced and a ISSR specimen, which are used for validating the overall analysis method, are presented in the first sub-section. Results for the rectangular cross-section reinforcement architectures, architectures 1 through 8 , are presented in the second sub-section. Results for triangular cross-section reinforcements, architectures 9 through 14, are presented in the third sub-section. Normalized maximum load and reinforcement load ratio are presented, along with a discussion of the mechanisms that influences the response.

\section{A. Validation analyses}

Test results and a two-dimensional finite-element analysis, based on the FRANC2D computer code, for one compact tension specimen [5] were compared with the current three-dimensional analysis. All subsequent references to experimental or two-dimensional finite element analysis results refer to Farley, et al [5].

Results for load, $\mathrm{P}$, as a function of change in surface crack length, $\Delta a$, from the three-dimensional finite element analysis for an unreinforced compact tension specimen are presented in Figure 3 and 
compared to the experimental and two-dimensional analysis results. Good agreement was achieved between the three-dimensional analysis results and the previously reported experimental and twodimensional analysis results. The shape of the predicted response curves is similar to experiment and twodimensional analysis predictions. The difference in predicted fracture strength between the threedimensional analysis and the two-dimensional analysis was approximately 4 percent. Predicted tunneling from the three-dimensional analysis was consistent in shape and size to that reported by Dawicki, et al [9]. Because CTOA criteria were used in the work by Dawicki, et al [9] and in the present work, resulting in similar response curves, it is believed that the level of discretization of the model and algorithm implemented are appropriate to model crack growth in aluminum compact tension specimens.

A three-dimensional finite element analysis of a reinforced specimen identical to one tested and analyzed by Farley et al [5], by using a two-dimensional analysis, was performed. The geometry of this reinforced specimen is similar to the specimen in Figure 1 and shown in Table 1 as reinforcement architecture one. The predicted relation between load and change in surface crack length curve for the three-dimensional analysis is presented in Figure 4 along with the experimental and two-dimensional analysis results from Farley et al [5]. Although the maximum load achieved was similar (approximately 2 percent difference), there is noticeable difference in the relation near peak load. That is, the threedimensional analysis predicted a substantially shorter crack length prior to failure than predicted by the two-dimensional analysis or as measured in the experiments. Additionally, the latter two results exhibited a plateau effect with a slight positive slope to failure. This plateau was attributed [5] to load sharing and transfer between the base material and the reinforcement, resulting in a 1 to 2 percent increase in maximum load. Neither the length of the plateau region nor its slope has been accurately quantified nor was further explanation provided by Farley et al [5].

Furthermore, crack propagation in a compact tension test is a somewhat discontinuous process whereby the crack grows unstably between successive applications of load (here the loading pin displacement) for a short duration before arresting. Depending upon the local material morphology where the crack arrests, the next increment in load required to begin the next crack increment may be disproportionately higher or lower than the mean value. The resulting response curve is thus frequently irregular, similar to that depicted in Figure 4. Furthermore, the final increment in crack growth, depicted in Figure 4, did not arrest prior to reinforcement failure and therefore the load level and crack length were not in static equilibrium, rather they were transient values. If this last increment in crack growth was not included, better agreement between the three-dimensional analysis and experimental results would be achieved.

Finally, the reasons for the differences between the two-dimensional and three-dimensional analyses are speculative and in some cases difficult to accurately assess. One possible reason for the differences between the predicted results is related to the differences in dimensionality of the analyses. In both analyses failure is defined when the first reinforcement element is predicted to fail. Failure predictions are based on a maximum strain failure criterion. In the two-dimensional analysis a single element represents material associated with the full thickness of the reinforcement, whereas in the three-dimensional analysis a single element represents a portion of the total thickness of the reinforcement. In the three-dimensional analysis the first element to fail occurred at the leading edge of the reinforcement at the interior corner which represents less than 25 percent of the first column of reinforcement elements in the Y-direction on the $\mathrm{X}-\mathrm{Z}$ plane. To achieve the same volume of failed reinforcement from the three-dimensional analysis as achieved in the two-dimensional analysis requires additional load pin displacement, resulting in further crack growth. Therefore, it is believed that the three-dimensional analysis as just described is deemed sufficient without further refinement or complex materials laws.

\section{B. Rectangular reinforcement}

Load as a function of change in surface crack length for each rectangular cross-section reinforcement architecture (architectures 1 thru 8) is presented in Figure 5. For comparison purposes the relation for the unreinforced case is included. The relations are terminated at the maximum load and in the case of the reinforced specimens this is when initial failure of the reinforcement occurs. All of the load versus increase in surface crack length relations for the rectangular reinforced specimens exhibited failure characteristics similar to those for the unreinforced specimen except, the relations for the reinforced specimens were shifted vertically, resulting in higher load for a given surface crack length. The maximum load for architectures 1, 2, 6, 7 and 8 were 16 to 18 percent higher than for the unreinforced specimen, as depicted in the bar graph in Figure 6. As indicated from Figure 5, the relation for architecture 3 (mid-surface 
reinforcement that was twice as thick and one-half as wide as architecture 2) and architecture 4 (full thickness reinforcement and 40 percent as wide as architecture 2) exhibited substantially higher load. These results were 28 and 32 percent, respectively higher than the maximum load of the unreinforced specimen, as illustrated in Figure 6.

Load sharing and transfer between the base material and the reinforcement was identified [5] as an important mechanism for explaining why compact-tension specimens with reinforced materials exhibited higher maximum load. In Figure 6 the ratio of the load in the reinforcement to the load in the pin at reinforcement failure, denoted herein as reinforcement load ratio, is presented for architectures 1 through 8 . Architectures 1, 2, 6, 7 and 8 exhibited load ratios between 50 and 62 percent. However, for architectures 3 and 4 the reinforcement load ratios of 85 and 88 percent, respectively, were obtained. The reinforcement load ratio trend was similar to the maximum load trend. That is, the more load shared and transferred to the reinforcement, the higher the maximum load.

Reinforcement load ratio was determined to be nearly a linear function of the change in surface crack length, as depicted in Figure 7 for architecture 1. The other architectures produced similar results and are therefore not presented. Contours of the strain component $\varepsilon_{y y}$ on the specimen's X-Z plane at four points (A through D) along the relation depicted in Figure 7 are presented in Figures 8. These cross-sections start just before the initial crack position and extend into the reinforced region. The pre-crack and yielded materials in the base material are shown in each cross section. The crack tip locus (crack front) through the thickness is depicted as a series of dots. The load level at point A corresponds to the level to cause the initial crack to propagate. At this point the crack profile through the thickness is straight, with extensive yielding of the base material ahead of the crack tip. The reinforcement load ratio at point $\mathrm{A}$ is approximately 35 percent.

As the surface crack length increased to points B and C, the reinforcement load ratio increased in a linear manner. Crack tip tunneling was evident at point B and was fully developed at point C. Yielding in the base material from the crack tip further extends between points B and C. The distance from the crack tip to the point of yielding in the base material was approximately constant as the surface crack length grew between points $\mathrm{C}$ and $\mathrm{D}$. At point $\mathrm{D}$, failure of the reinforcement, the reinforcement load-ratio is approximately 60 percent. Considerable yielding in the base material occurs beneath the reinforcement. Similar responses were obtained for all reinforcement architectures.

Contours of extensional strain component $\varepsilon_{y y}$ in the X-Z plane near the reinforcement at the maximum load is presented in Figures 9a-i for all rectangular architectures. For comparison purposes the baseline unreinforced specimen is included with the reinforced specimens, Figure 9a. For a given strain level, the strain contour curves in the thickness direction, extending farthest in the X-direction at the mid-plane. The curved shape of this contour is consistent with the shape of the crack through the thickness of the specimen, and is a manifestation the tunneling phenomena mentioned earlier. The strain contours for architecture 1, Figure $9 \mathrm{~b}$, are similar in shape and location along the $\mathrm{X}$-axis as found in the unreinforced case. The reinforcement causes the strain contour to become less curved through the thickness due to the increased local stiffening. The increase in local stiffness requires an increase in load to be applied to achieve the necessary strain to cause failure at the interior corner of the reinforcement.

The objective of analyzing architecture 2 was to determine whether spatial location of the reinforcement had any influence on maximum load and general response. Architecture 2, as depicted in Figure $9 \mathrm{c}$, created a further flattening of the strain contour. Yielding of the base material occurred between the reinforcement and the specimen's outer surface, such that the crack position in the X-direction outside the reinforcement exceeds the crack position near the specimen mid-plane. The effect of the reinforcement's stiffness on the response of the local base material is such that the application of additional load is necessary to cause failure. The maximum load for architecture 2 was 17 percent higher than that of the unreinforced specimen, and essentially identical to that of architecture 1. Although there were differences in the spatial distribution of the extensional strain field adjacent to the reinforcement, the location of the reinforcement had essentially no affect on maximum load and their reinforcement loadratios were the same at 61 percent.

Reinforcement architecture 3 was similar to architecture 2 except architecture 3's reinforcement was twice as thick and one-half as wide, thus maintaining a constant reinforcement cross-sectional area. The objective was to determine the effect of reinforcement thickness on maximum load. Architecture 3's twenty-eight percent higher maximum load was 55 percent higher than the next best architecture. The strain contours, depicted in Figure 9d, were nearly straight through the thickness, creating a situation where a significant portion of the leading edge of the reinforcement material was at or near its failure strain when 
the reinforcement failed. Furthermore, the contour intervals in the reinforcement were narrower, which means a larger percentage of the reinforcement was at a higher average strain. These findings are consistent with the calculated reinforcement load-ratio of 85 percent as compared to 61 percent for architecture 2 .

Reinforcement architecture 4 continued the trend of thicker but narrower reinforcements. In this case the reinforcement was full thickness. The calculated maximum load and load ratio were 32 and 88 percent higher, respectively, than that of the unreinforced specimen. The strain contours, depicted in Figure 9e, has a similar level of straightness through the thickness as exhibited by architecture 3 .

Reinforcement architecture 5 is similar to that of architecture 4 except the width of architecture 5 is one-half that of architecture 4, resulting in one-half the reinforcement area. The maximum load was approximately 18 percent higher than the unreinforced specimen. Maximum load did not scale linearly with reinforcement cross-sectional area, that is, it exhibited a slightly more efficient response. The load ratio for architecture 5 was 62 percent, substantially less than the 88 percent exhibited by reinforcement architecture 4 . The maximum load and load ratio exhibited by architecture 5 was similar in magnitude to that exhibited by architectures 1,2,6 and 7 even though architecture 5 had one-half of the reinforcement area.

Reinforcement architecture 6 was analyzed to understand the affect of rounding the corner of the reinforcement where failure occurred. The maximum load was 18 percent higher than the unreinforced specimen and only slightly out-performed architecture 1, which produced 17 percent higher maximum load. The reinforcement load-ratio for architecture 6 was 62 percent as compared to 61 percent for architecture 1 . These slight improvements in maximum load and reinforcement load-ratio were achieved even though architecture 6 had 1.7 percent less cross-sectional area due to the corner rounding. Strain contours between architectures 1, Figure 9b, and 6, Figure 9g, were similar. The rounding of the corner caused a slightly higher amount of reinforcement material to be at or near the failure strain level when the reinforcement failed, hence the slightly higher maximum load.

The objective of reinforcement architecture 7 was to investigate the influence of segmenting reinforcement. The reinforcement segments have square cross-sectional area (above the symmetry plane) and are of equal thickness as the thick reinforcement in architecture 3 . The segments have spacing equal to one-half the thickness of the total specimen. The maximum load was 17 percent higher than produced by the unreinforced specimen and was the same as produced by architectures 1 and 2. Even though the maximum load for architecture 5 was the same as architectures 1 and 2 the reinforcement load-ratio at failure was 58 percent, approximately 4 percent less. From the strain contours, depicted in Figure 9h for architecture 5, only the first three of the six reinforcement segments are carrying a significant portion of the load. The thickness of the first segment produced a similar effect on the strain contours as occurred in architecture 3. That is the strain contour is nearly straight as compared to highly curved behavior exhibited by architectures 1 and 5, and to a lesser extent architecture 2. Also, based upon the strain contours, the first reinforcement segment seems to be reacting more load across its width than a comparable length of architecture 3.

Reinforcement architecture 8 was similar to that of architecture 7, except one-half the number of segments was included. The maximum load and load ratio for architecture 7 were 16 and 50 percent, respectively. The strain contours, as depicted in Figure 9i, are nearly identical as those produced by architecture 7. Although there was a doubling in reinforcement cross-section area between architectures 8 and 7 the performances were similar. This trend is similar to that obtained for architectures 4 and 5 and suggests that reinforcement width has less importance than reinforcement height.

The important findings relative to rectangular reinforcements are:

1) Thick and narrow reinforcements produce higher maximum loads than thin and wide reinforcements.

2) Tailoring the shape of the reinforcement's leading edge, especially near the surface of the specimen, can increase maximum load.

3) Narrow reinforcement segments may increase load transfer efficiency.

\section{Triangular reinforcement}

The load versus increase in surface crack length relations for all triangular reinforcement architectures (9 through 14) are depicted in Figure 10, along with the relation for the unreinforced specimen. All of the triangular reinforcement architectures produced relations similar to the unreinforced case, except the relations for the reinforced cases were shifted vertically. This, recall, was the situation with the rectangular 
reinforcements. The range in normalized maximum load for architectures 9 through 14 was between 13 and 16 percent greater than for the unreinforced case, as shown in Figure 11. None of the triangular reinforcements exhibited higher maximum load than the lowest load for the rectangular reinforcement. Reinforcement load-ratios, as shown in Figure 11, were generally less than those produced by the rectangular reinforcements, except for reinforcement architectures 13 and 14, which were comparable to most of the rectangular reinforcements.

Because the performances of the triangular reinforcements were generally inferior to those of the rectangular reinforcements a detail discussion of their response is replaced with a summary of the overall findings.

1) A sharp leading edge reinforcement had less influence on maximum load than a blunt edge.

2) The application of an aluminum alloy at the leading edge had no effect on maximum load. However, the application of the alloy created a blunt leading edge for the higher stiffness reinforcement, which resulted in a higher maximum load than a triangular reinforcement with a sharp leading edge.

3) A triangular reinforcement positioned at the specimen surface, such as architecture 9 and 14, exhibited higher maximum load and reinforcement load-ratios than comparable architectures positioned at the specimen mid-plane, architectures 10 and 11 , respectively.

\section{Conclusions}

An investigation of fourteen different in-situ selective reinforcement architectures were investigated and compared to the performance of a geometrically comparable unreinforced compact tension specimen. The performance metric used for comparison was maximum load. All of the in-situ selective reinforcement architectures produced superior maximum load compared to the unreinforced specimen. The range in performance improvement was 13 to 32 percent. The rectangular reinforcement architectures produced 16 to 32 percent improvement in performance relative to the unreinforced case and the triangular reinforcement architectures produced 13 to 16 percent improvement in performance. Blunt leading edge reinforcements were superior to sharp leading edge reinforcements. Thick and narrow rectangular reinforcements exhibited results superior to all other architectures. Tailoring the leading edge of the reinforcement when it is located at the specimen surface can influence the local strain distribution in a way to have more of the reinforcement at or near the failure strain when the reinforcement fails. Segmenting thick and narrow reinforcements has the potential to be efficient reinforcement architecture. 


\section{References}

${ }^{1}$ Harris, C. E., "NASA Aircraft Structural Integrity Program,” NASA TM-102637, April 1990.

${ }^{2}$ Norris, G. and Wagner, M., Boeing 777 - The Technological Marvel, MBI Publishing Company, Osceola, WI, 2001.

${ }^{3}$ Boeing News Release: “Boeing 7E7 Structure Will Be Made of Composite Materials,” June 12, 2003.

http://www.boeing.com/news/releases/2003/q2/ nr 030612g.html Accessed June 27, 2005.

${ }^{4}$ Garratt, M. D., Bucci, R. J. and Kulak, M., "FCG Evaluation of New Lower Wing Concept," AeroMat Conference, Seattle, WA, June 7-10, 2004.

${ }^{5}$ Farley, G. L., Newman, J. A., and James, M. A., "Selective Reinforcement to Improve Fracture Toughness and Fatigue Crack Growth Resistance in Metallic Structures," AIAA Paper No. 2004-1924, 45 ${ }^{\text {th }}$

AIAA/ASME/ASCE/AHS/SDM Conference, Palm Springs, CA, April 19-22, 2004.

${ }^{6}$ Farley, G. L., "Selective Reinforcement to Enhance the Structural Performance of Metallic Compression Panels," AIAA Paper No. 2004-2050, 45 ${ }^{\text {th }}$ AIAA/ASME/ASCE/AHS/SDM Conference, Palm Springs, CA, April 19-22, 2004.

${ }^{7}$ Farley, G. L., and Seshadri, B. R., "Performance Enhancement Using Selective Reinforcement for Metallic Single- and Multi-Pin Loaded Holes," AIAA Paper No. 2005-2025, $46^{\text {th }}$ AIAA/ASME/ASCE/AHS/SDM Conference, Austin, TX, April 18-21, 2005.

${ }^{8}$ Anon., ABAQUS users manual, Hibbgitt, Karlsson and Sorensen, Inc., 2000.

${ }^{9}$ Dawicke, D. S., Sutton, M. A., Newman, Jr., J. C. And Bigelow, C. A., "Measurement and Analysis of Critical CTOA for an Aluminum Alloy Sheet," NASA TM 109024, September 1993. 
Table 1A. Rectangular reinforcement architectures

\begin{tabular}{|c|c|c|}
\hline No. & Architecture & Rationale \\
\hline 1. & 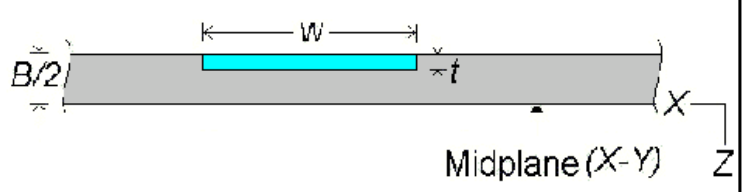 & $\begin{array}{l}\text { Baseline } \\
\text { reinforcement }\end{array}$ \\
\hline 2. & 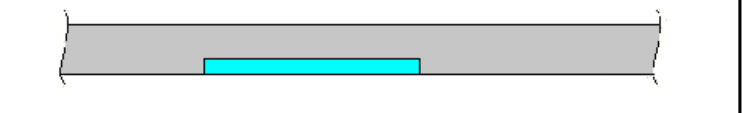 & $\begin{array}{c}\text { Influence of } \\
\text { spatial location }\end{array}$ \\
\hline 3. & $\frac{* 10.5 \mathrm{~W}}{\sqrt{12 t}}$ & $\begin{array}{l}\text { Influence of } \\
\text { reinforcement } \\
\text { thickness }\end{array}$ \\
\hline 4. & $\stackrel{0.4 w \leftarrow}{2.5 t}$ & Full Thickness \\
\hline
\end{tabular}

Base material 7075-T6 Al

Table 1B. Rectangular reinforcement architectures

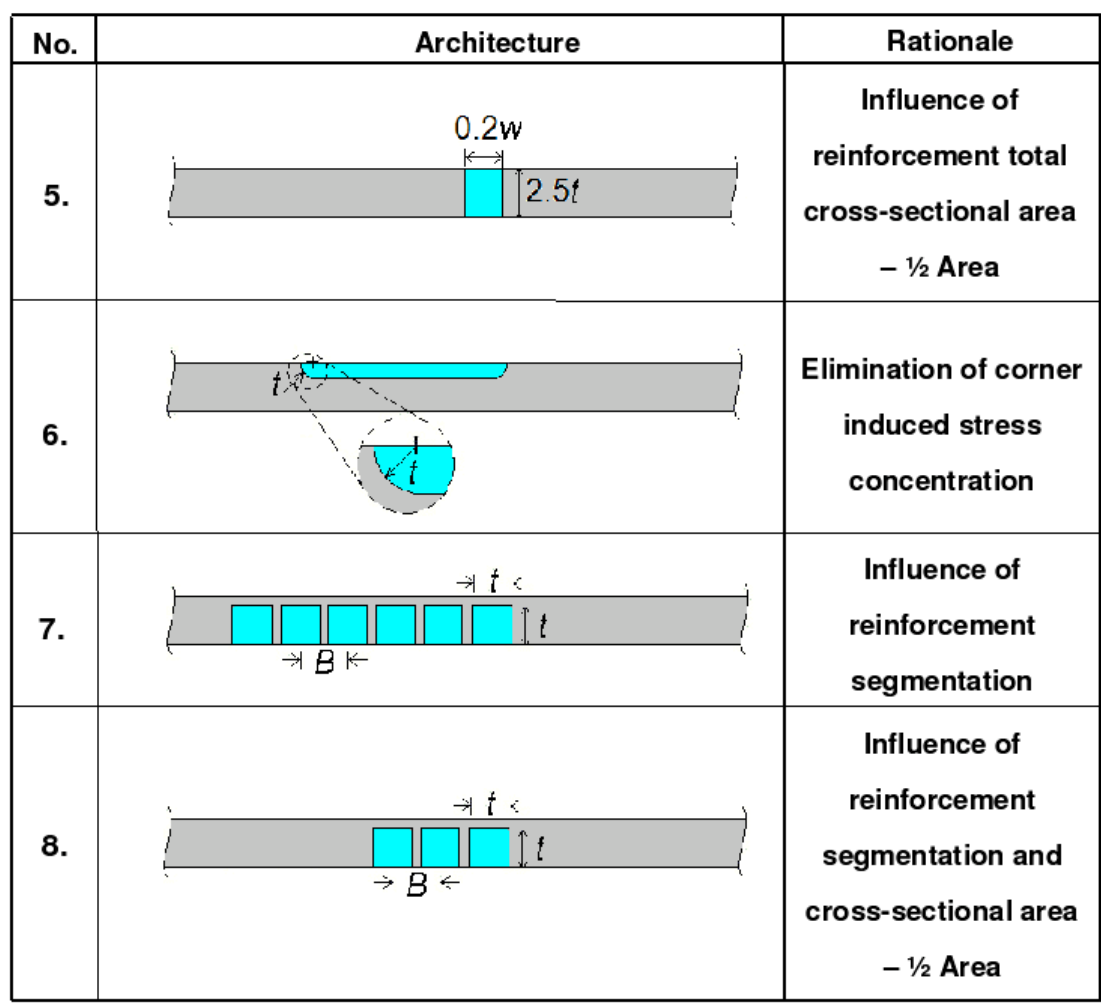

Unidirectional reinforcement

Base material 7075-T6 Al 
Table 2. Triangular reinforcement architectures

\begin{tabular}{|c|c|c|}
\hline No. & Architecture & Rationale \\
\hline 9. & $\frac{k \quad w \mid}{\text { Midplane }(X-V)} x$ & $\begin{array}{l}\text { Influence of } \\
\text { shape leading } \\
\text { edge }\end{array}$ \\
\hline 10. & 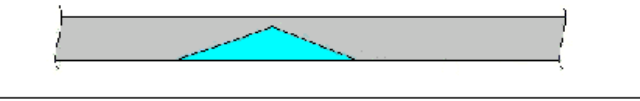 & $\begin{array}{c}\text { Influence of spatial } \\
\text { location }\end{array}$ \\
\hline 11. & 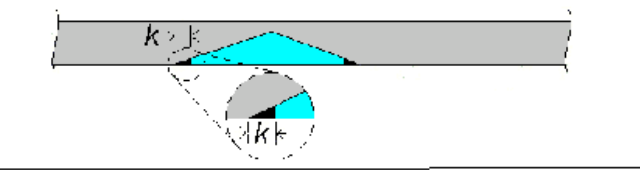 & $\begin{array}{l}\text { Influence of } \\
\text { alternative leading } \\
\text { edge material }\end{array}$ \\
\hline 12. & $k: 1$ & $\begin{array}{l}\text { Influence of } \\
\text { alternative leading } \\
\text { edge material }\end{array}$ \\
\hline 13. & $2.5 k$ & $\begin{array}{l}\text { Influence of length } \\
\text { of leading edge } \\
\text { length }\end{array}$ \\
\hline 14. & $k=-$ & $\begin{array}{c}\text { Influence of } \\
\text { alternative material }\end{array}$ \\
\hline
\end{tabular}

Unidirectional

reinforcement

Base material -

7075-T6 Al

$1100-\mathrm{Al}$

Al - Li 
Table 3. Material properties of materials used in analysis.

\begin{tabular}{|c|c|c|c|}
\hline Material & $\begin{array}{c}\text { Elastic } \\
\text { properties }\end{array}$ & $\begin{array}{c}\text { Yield / failure } \\
\text { values }\end{array}$ & $\begin{array}{c}\text { Represented in } \\
\text { analysis }\end{array}$ \\
\hline $\begin{array}{c}\text { 7075-T6 } \\
\text { Aluminum }\end{array}$ & $\begin{aligned} E & =10.0 \mathrm{Msi} \\
G & =3.85 \mathrm{Msi}\end{aligned}$ & $\begin{array}{c}\text { Yield stress }=72.5 \mathrm{ksi} \\
\text { Yield strain }=0.00725 \\
\text { in } / \mathrm{in}\end{array}$ & $\begin{array}{c}\text { Isotropic elastic-plastic } \\
\text { material }\end{array}$ \\
\hline $\begin{array}{l}\text { Unidirectional } \\
\text { composite } \\
\text { (Fiber volume } \\
\text { fraction }=50 \% \text { ) }\end{array}$ & $\begin{array}{rlrl}\mathrm{E}_{11} & =35.0 \mathrm{Msi} & \mathrm{v}_{13}=\mathbf{0 . 2 5} \\
\mathrm{E}_{22}=19.0 \mathrm{Msi} & \mathrm{G}_{12}=6.84 \mathrm{Msi} \\
\mathrm{E}_{33}=35.0 \mathrm{Msi} & \mathrm{G}_{23}=3.85 \mathrm{Msi} \\
v_{12}=0.14 & \mathrm{G}_{13}=\mathbf{0 . 2 5} \mathrm{Msi} \\
v_{23}=\mathbf{0 . 3 0} & & \end{array}$ & $\begin{array}{l}\text { Fiber failure stress = } \\
\qquad 250.0 \mathrm{ksi} \\
\text { Fiber failure strain = } \\
\quad 0.00714 \mathrm{in} / \mathrm{in}\end{array}$ & $\begin{array}{l}\text { Orthotropic linear- } \\
\text { elastic material }\end{array}$ \\
\hline 1100 Aluminum & $\begin{array}{c}\mathrm{E}=10.0 \mathrm{Msi} \\
\mathrm{v}=0.3 \mathrm{G}=3.85 \mathrm{Msi}\end{array}$ & $\begin{array}{l}\text { Yield stress }=22.0 \mathrm{ksi} \\
\text { Yield strain }=0.00725 \\
\text { in } / \mathrm{in}\end{array}$ & $\begin{array}{c}\text { Isotropic elastic-plastic } \\
\text { material }\end{array}$ \\
\hline $\begin{array}{l}\text { Aluminum - } \\
\text { Lithium }\end{array}$ & $\begin{array}{c}\mathrm{E}=11.0 \mathrm{Msi} \\
\mathrm{v}=0.3 \mathrm{G}=4.23 \mathrm{Msi}\end{array}$ & Yield stress = $94.5 \mathrm{ksi}$ & $\begin{array}{c}\text { Isotropic elastic-plastic } \\
\text { material }\end{array}$ \\
\hline Steel & $\begin{array}{c}\mathrm{E}=\mathbf{3 0 . 0} \mathrm{Msi} \\
\mathrm{v}=0.3 \mathrm{G}=11.50 \mathrm{Msi}\end{array}$ & N/A & $\begin{array}{c}\text { Isotropic elastic } \\
\text { material }\end{array}$ \\
\hline
\end{tabular}


(a) - Compact-tension (CT) specimen

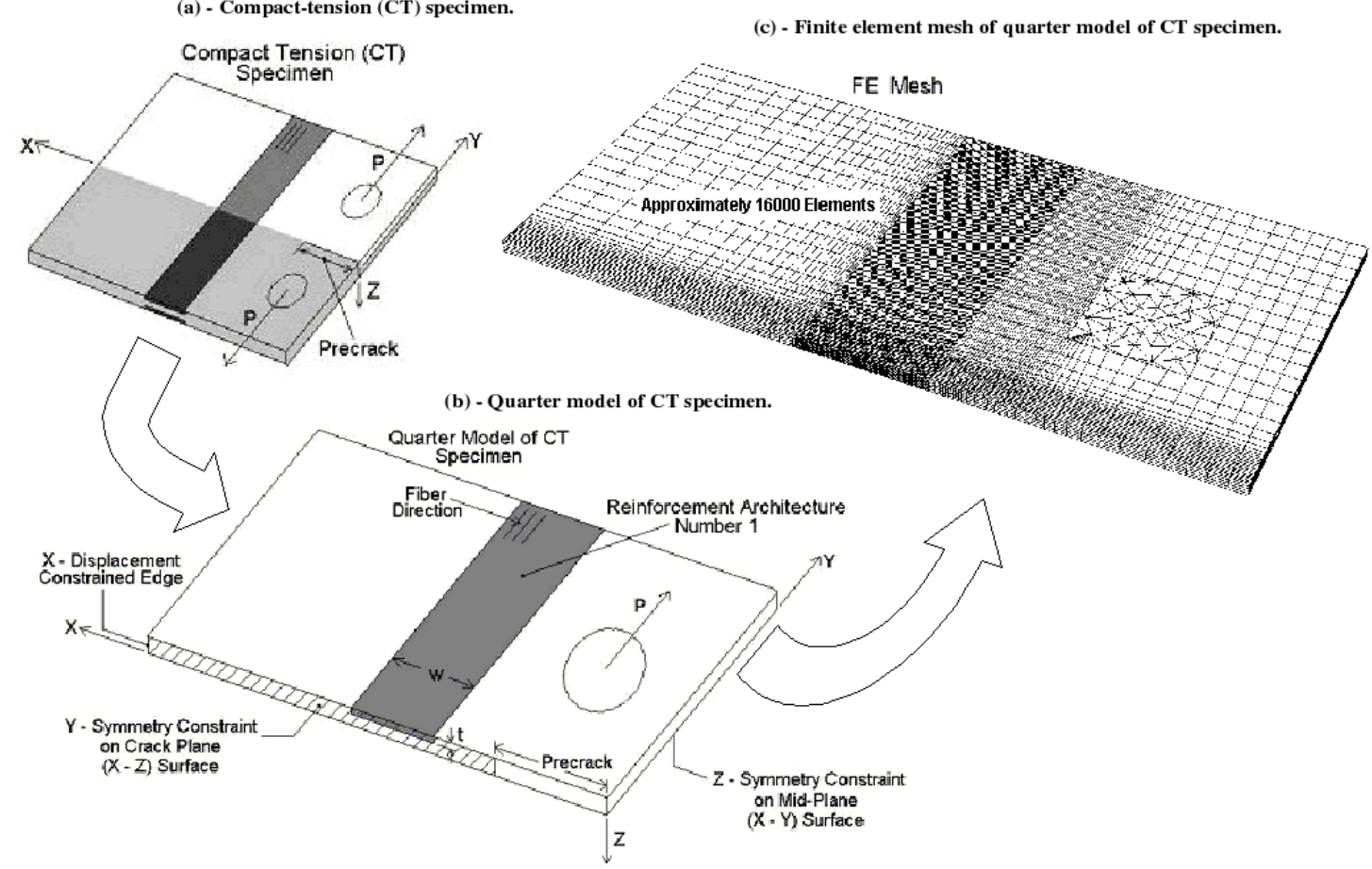

Figure 1. Compact tension specimen and typical finite element model.
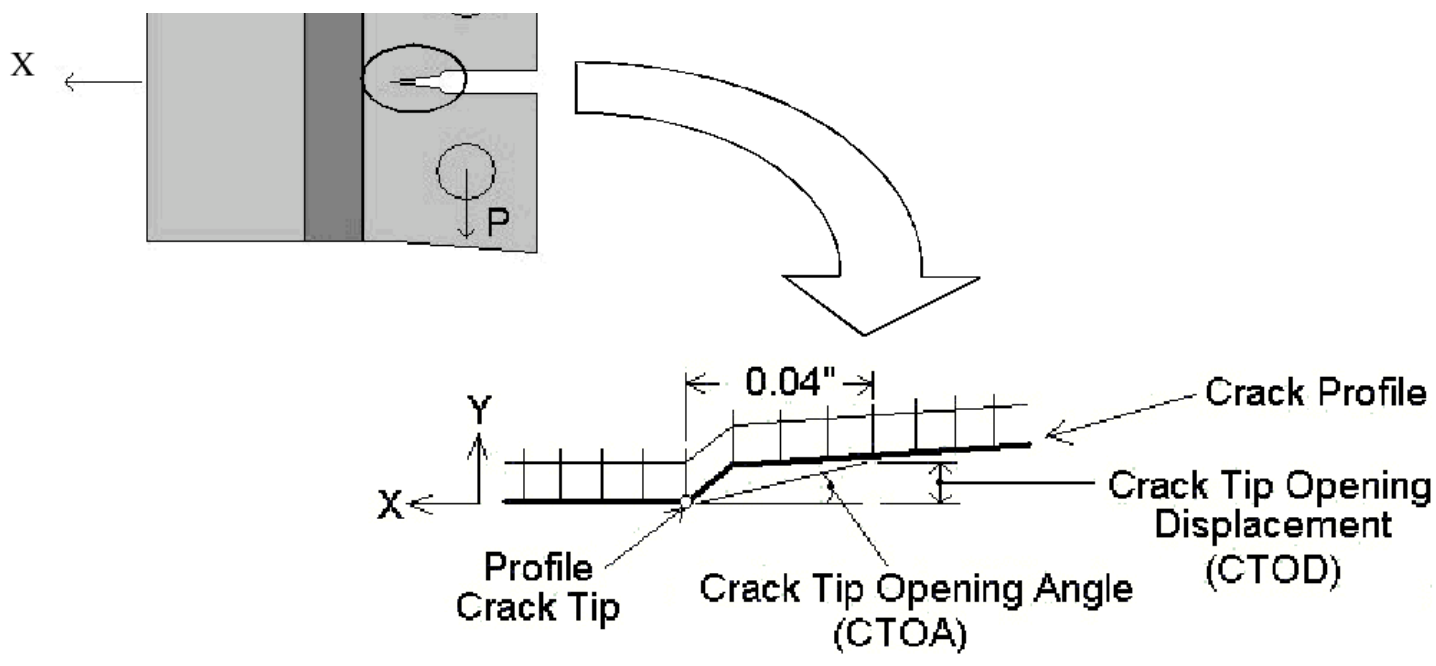

Figure 2. Measurement of CTOA 


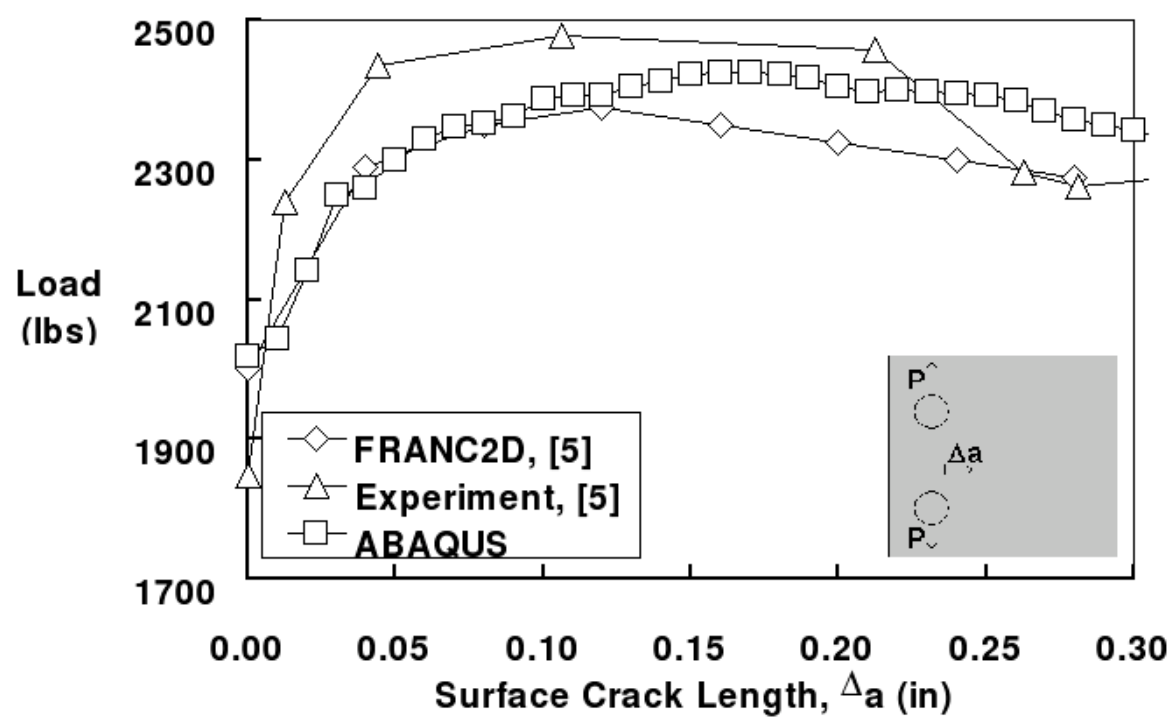

Figure 3. Load as a function of surface crack length for unreinforced validation analysis 


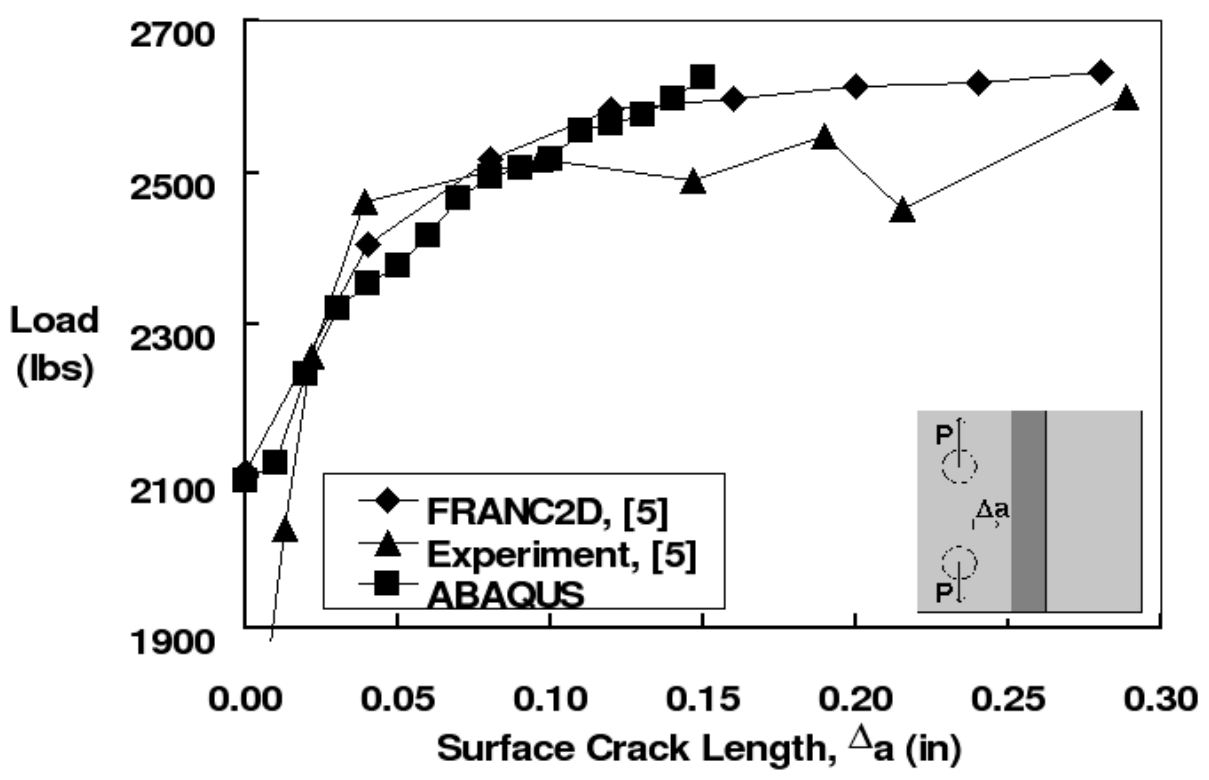

Figure 4. Load as a function of surface crack length for reinforced validation analysis 


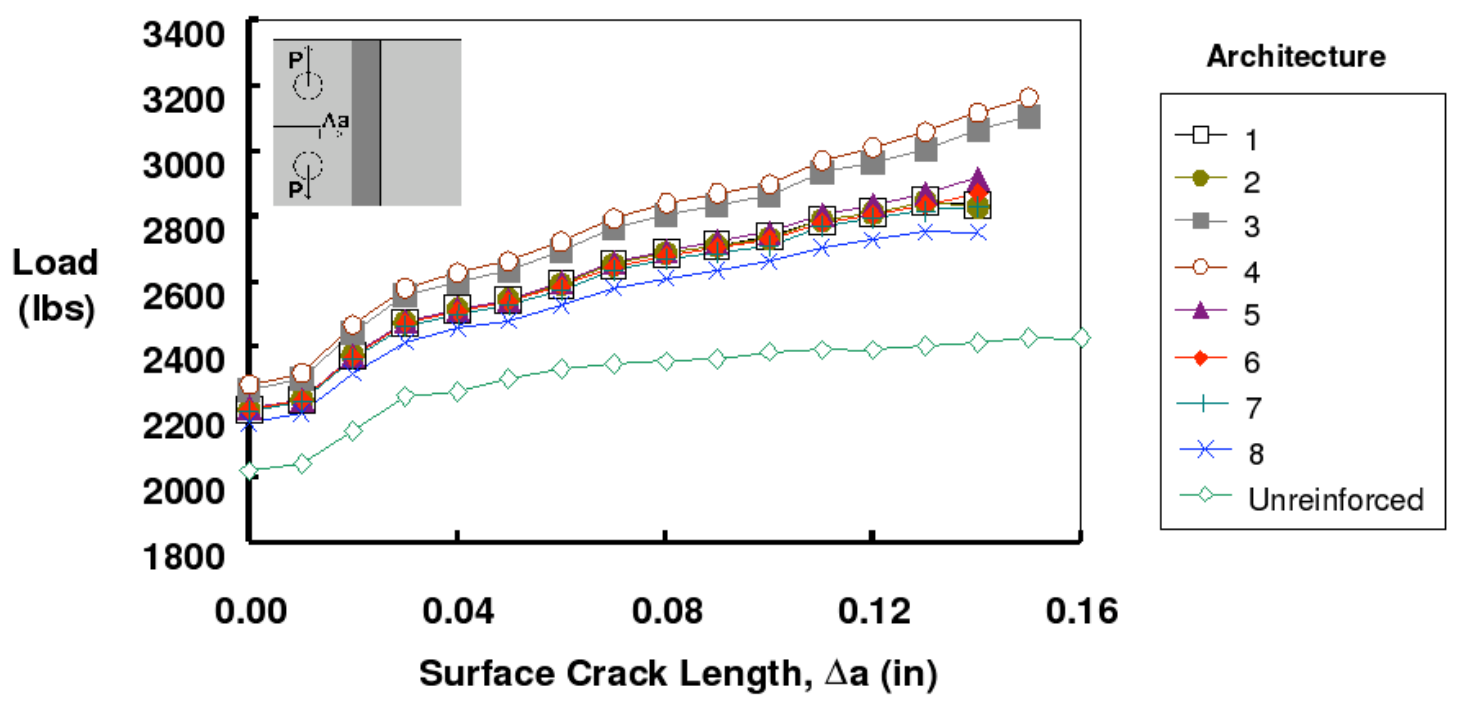

Figure 5. Load as a function of surface crack length for reinforcement architectures 1 thru 8.

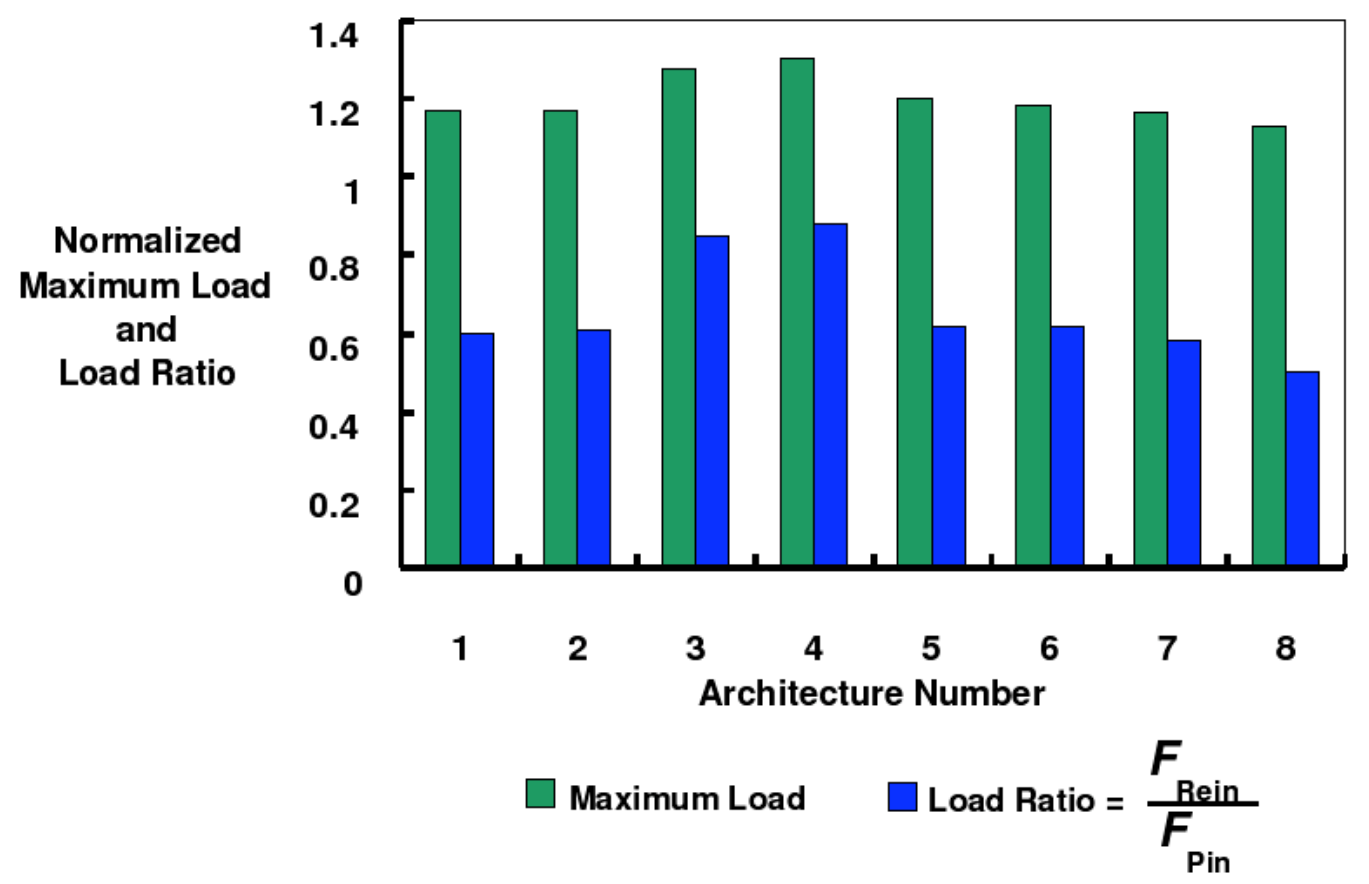

Figure 6. Normalized maximum load and reinforcement load-ratio for reinforcement architectures 1 thru 8. 


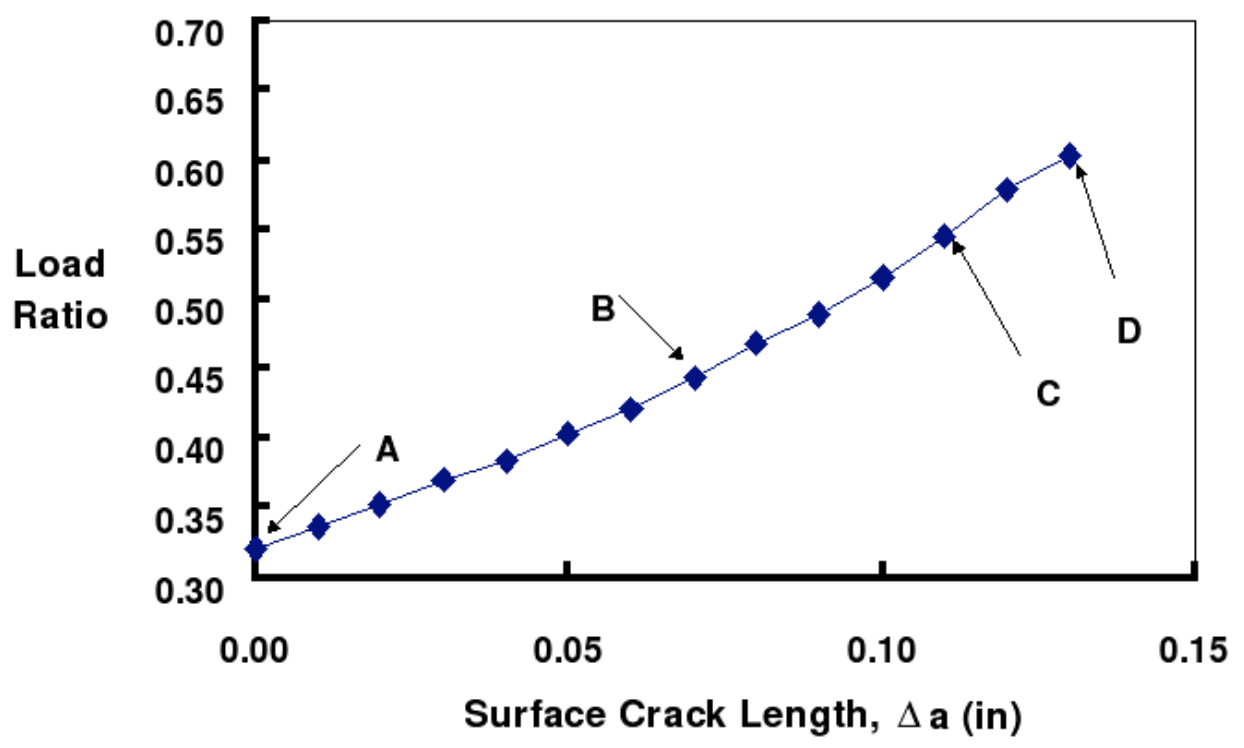

Figure 7. Reinforcement load-ratio as a function of surface crack length for reinforcement architecture 1 . 


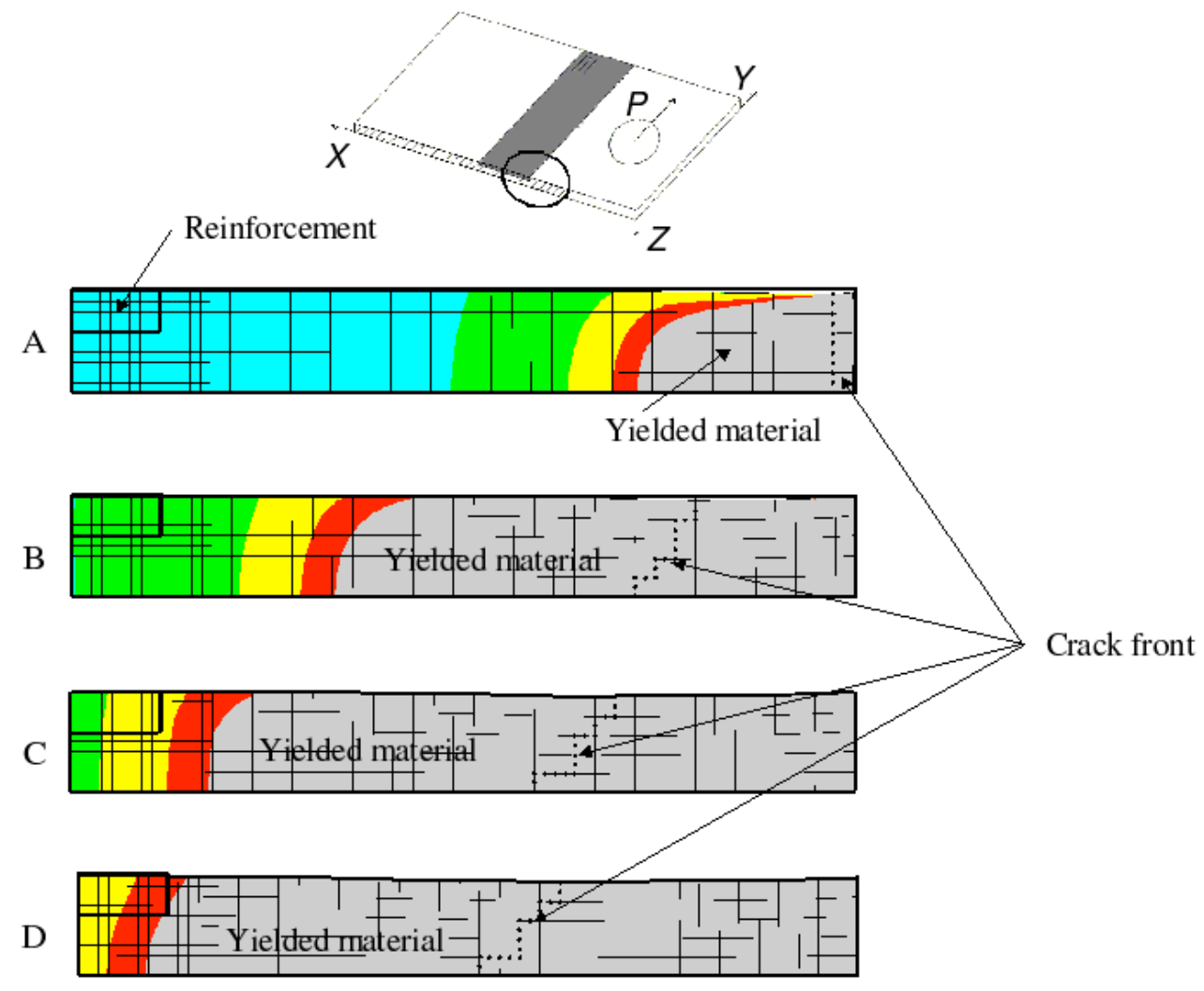

Figure 8. $\varepsilon_{\mathrm{yy}}$ strain contours on crack surface at four load-ratios for reinforcement architecture 1. 

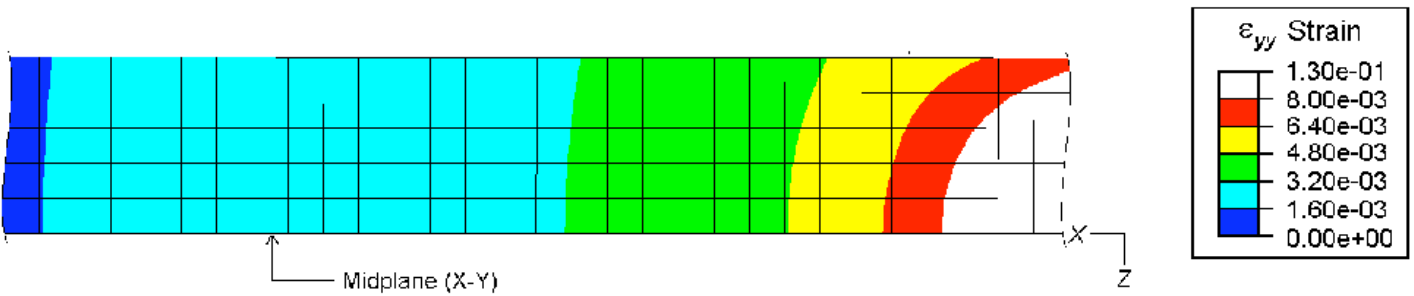

Figure 9a. $\varepsilon_{\mathrm{yy}}$ strain contours on crack surface at maximum load (non-reinforced specimen).
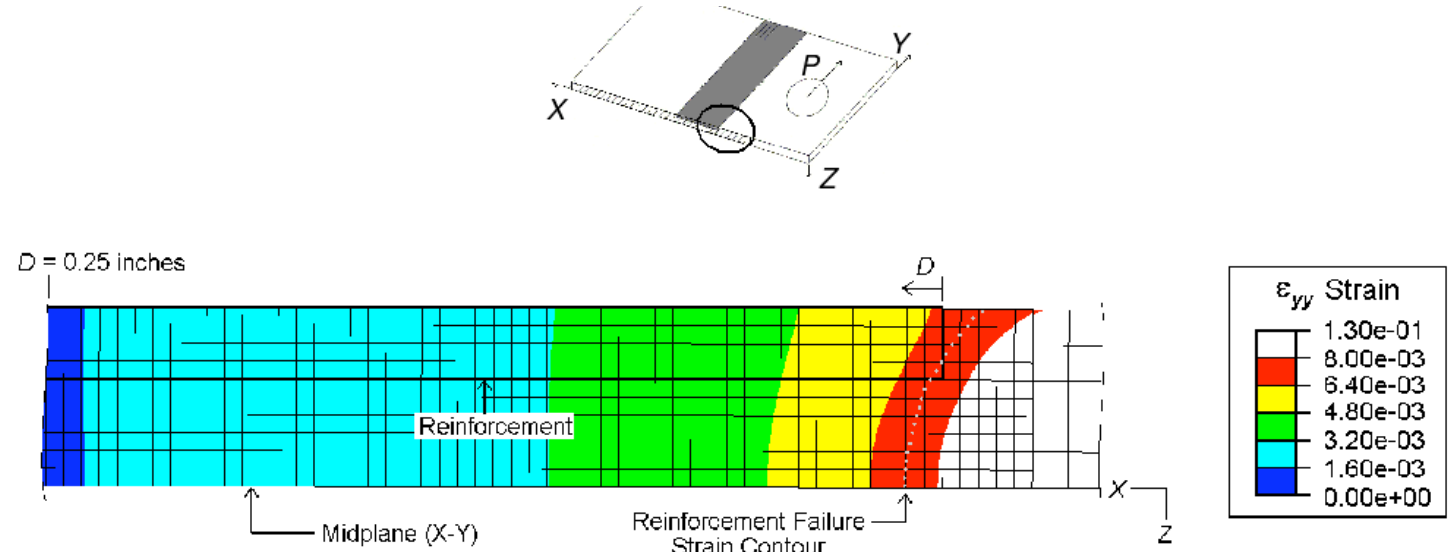

Figure $9 \mathrm{~b} . \varepsilon_{\mathrm{yy}}$ strain contours on crack surface at maximum load (reinforcement architecture 1).

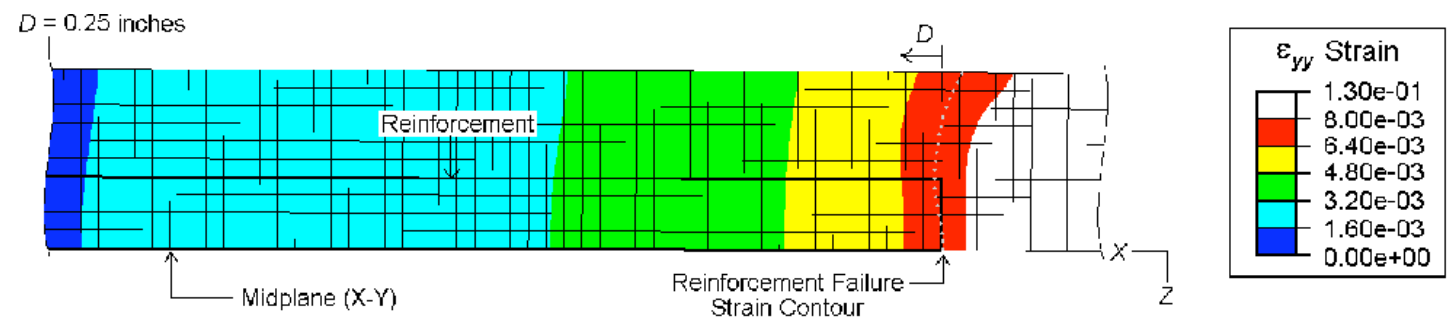

Figure 9c. $\varepsilon_{\mathrm{yy}}$ strain contours on crack surface at maximum load (reinforcement architecture 2). 


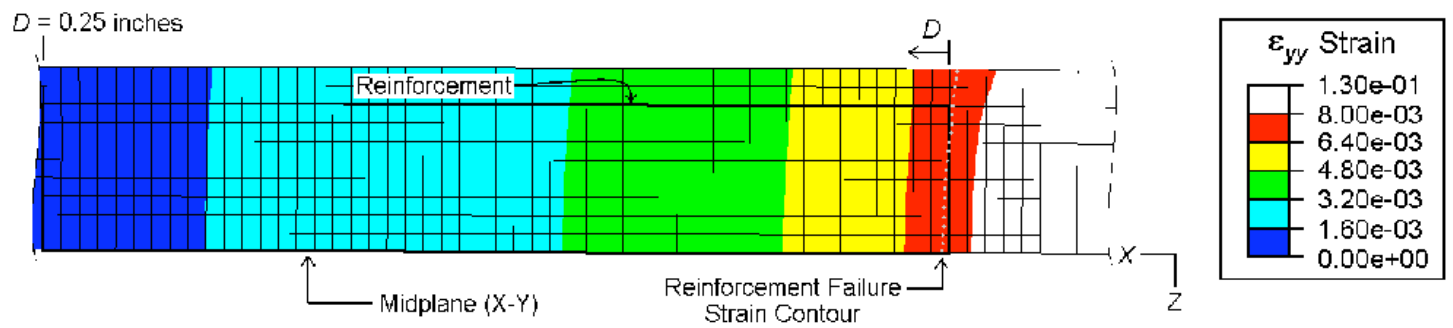

Figure 9 d. $\varepsilon_{\mathrm{yy}}$ strain contours on crack surface at maximum load (reinforcement architecture 3).

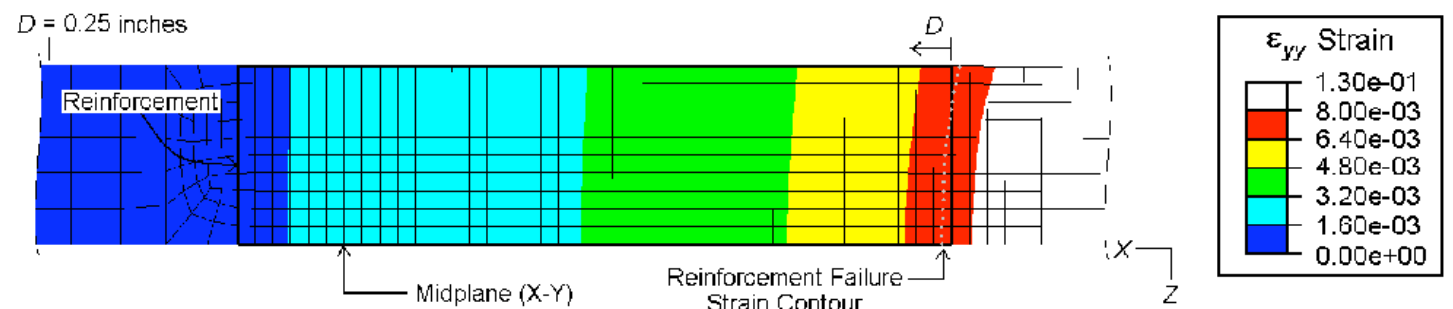

Figure 9e. $\varepsilon_{\mathrm{yy}}$ strain contours on crack surface at maximum load (reinforcement architecture 4).

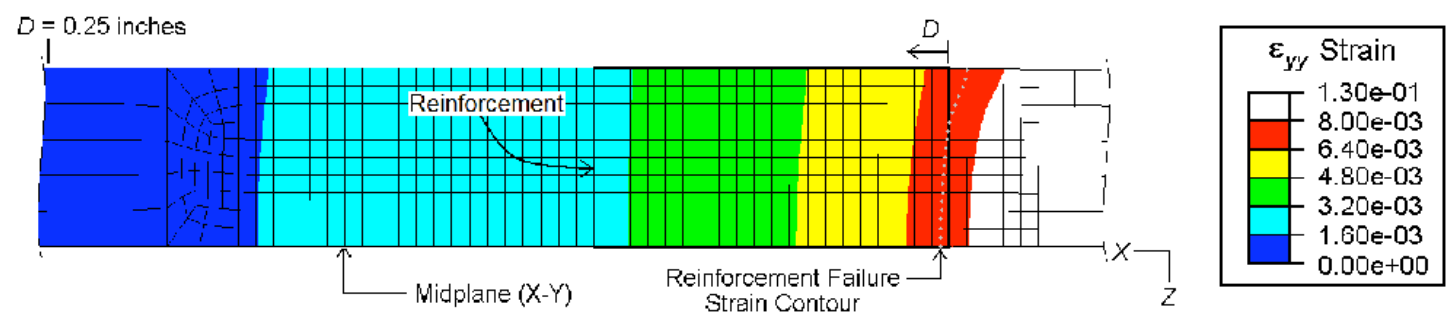

Figure 9f. $\varepsilon_{\mathrm{yy}}$ strain contours on crack surface at maximum load (reinforcement architecture 5). 


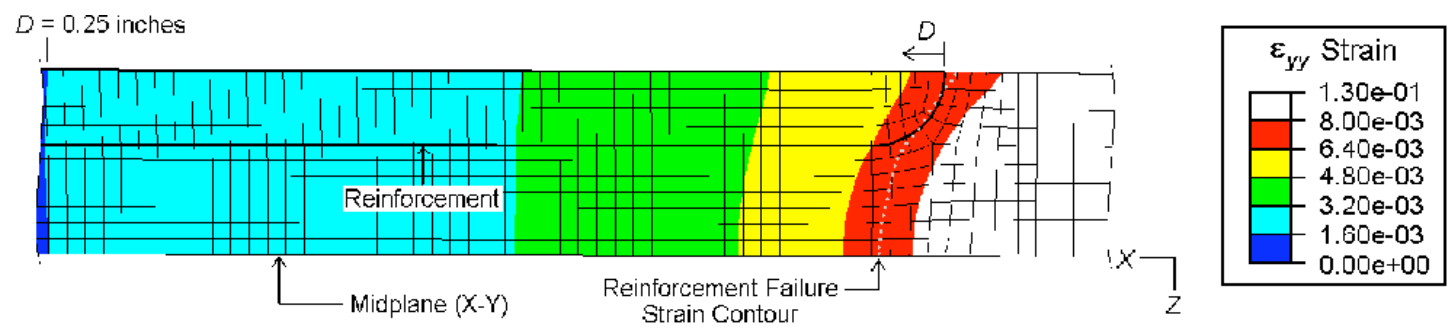

Figure 9g. $\varepsilon_{\mathrm{yy}}$ strain contours on crack surface at maximum load (reinforcement architecture 6).

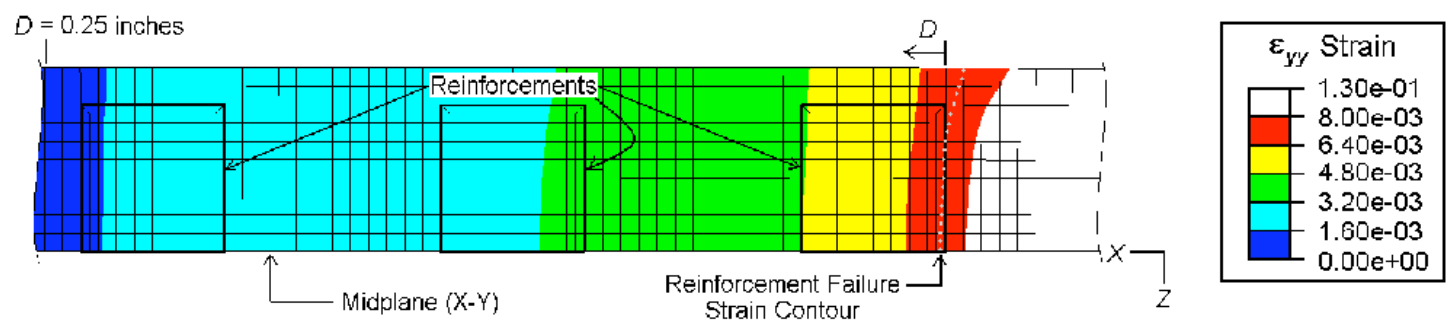

Figure 9h. $\varepsilon_{\mathrm{yy}}$ strain contours on crack surface at maximum load (reinforcement architecture 7).

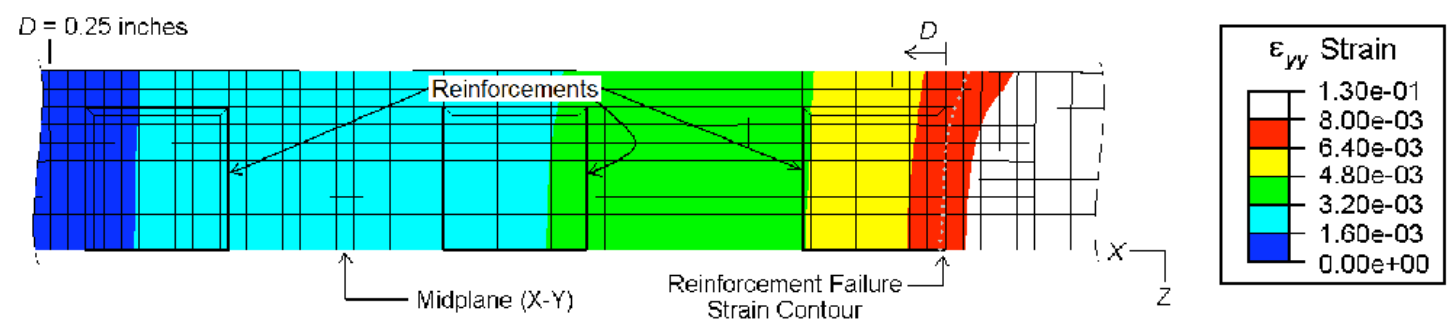

Figure 9i. $\varepsilon_{\mathrm{yy}}$ strain contours on crack surface at maximum load (reinforcement architecture 8). 


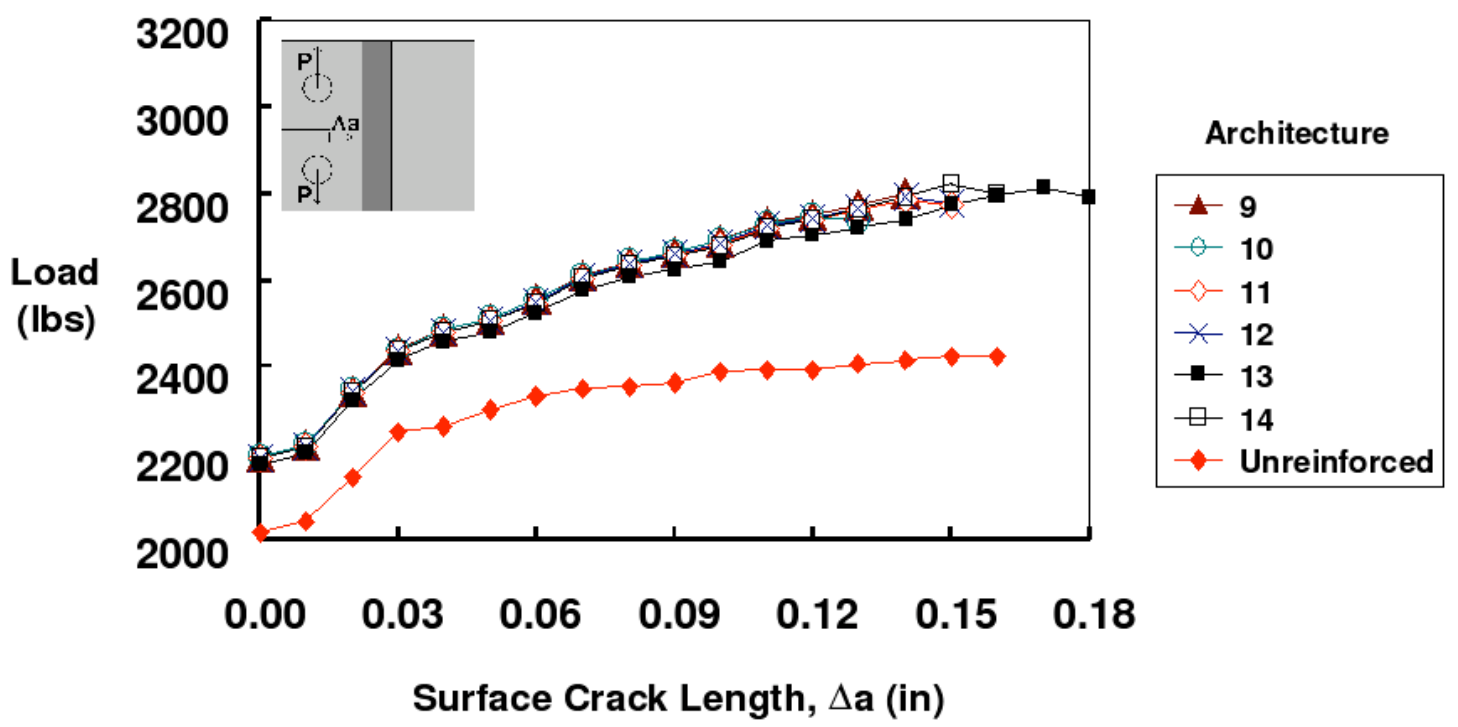

Figure 10. Load as a function of surface crack length for reinforcement architectures 9 thru 14.

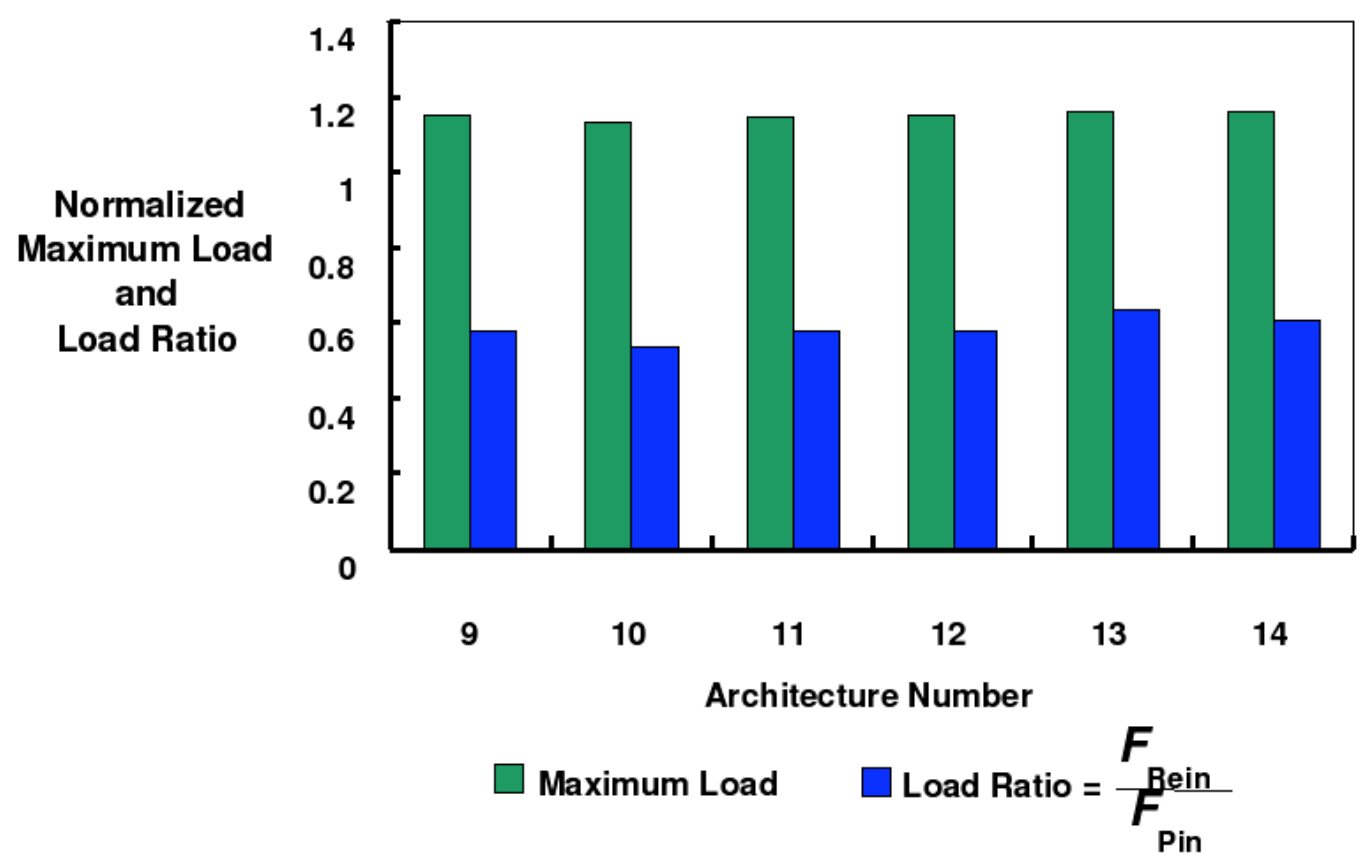

Figure 11. Normalized maximum load and reinforcement load-ratio for reinforcement architectures 9 thru 14. 